\title{
RANCANG BANGUN PABRIK PLASTIK DARI BAHAN POLIETILEN FOOD GRADE
}

Oleh : Irene Sri Sukaeni, Arum Yuniari

Abstract

The aim of this research is to find out process of production and the relation between cost, sell price and percentage of break even point. Production of capacity planned is 43.200 bottles perday, so that in a year with 288 workday, ca pacity produced is 12.400 .000 bottles. The economical calculation are as follows the total capital is fixed capital + working capital = Rp. 1.489.200.308,00; the total production cost is variable cost a year + fixed cost a year $=R p$. 3.532.949.829,00;. The manufacturing cost $=$ Rp. $285,00 /$ bottle, the probit calculation before taxing is Rp. $466.230 .171,00$ and after taxing is Rp. 372.984.136, the pay out period calculation consist of the percentage of profit to return the capital (rate of return) before taxing is $31,30 \%$, after taxing is $25,04 \%$ and the pay out period before taxing 2 year 11 months, after taxing 3 year 7 months; the break even calculation consist of break even point is Rp. 1.988.929.421,00; the percentage of break even point is $49,73 \%$ and the capacity of break even point is 6.166 .250 bottles.

\section{INTISARI}

Penelitian ini bertujuan untuk mengetahui proses produksi dan hubungan antara biaya, harga jual dan persentase batas rugi laba. Kapasitas produksi direncanakan sebesar 43.200 botol perhari, sehingga dalam 1 tahun dengan 288 hari kerja kapasitas yang dihasilkan 12.400 .000 botol. Dari analisa ekonomi diperoleh hasil sebagai berikut : Total modal yang terdiri dari modal tetap dan modal kerja $=$ Rp. $1.489 .200 .308,00$, biaya produksi yang terdiri dari biaya tidak tetap 1 tahun dan biaya tetap 1 tahun = Rp. 3.532.949.829,00. Harga pokok produksi $=$ Rp. 285,00/botol, keuntungan sebelum pajak Rp. 466.230.171,00 dan sesudah pajak Rp. 372.984.136,00. Persen keuntungan untuk mengembalikan modal sebelum pajak 2 tahun 11 bulan, sesudah pajak 3 tahun 7 bulan. Perhitungan nilai batas rugi laba $=\mathrm{Rp}$. 1.988.929.421,00 dan persentase batas rugi laba $49,73 \%$ serta kapasitas batas rugi laba $=6.166 .250$ buah botol. 


\section{PENDAHULUAN}

Jenis-jenis botol bila ditinjau dari bahan pembuatnya ada bermacammacam yaitu botol gelas, botol logam dan botol plastik. Botol plastik mempunyai prospek yang cerah sebagai salah satu wadah disamping botol dari bahan jenis lainnya. Bahkan dengan adanya penelitian dan pengembangan yang terus menerus dibidang pembuatan botol plastik maka kekurangan yang ada pada botol plastik dapat dihindarkan sehingga penggunaannyapun semakin meluas, sehingga kemungkinan dapat menggantikan botol dari jenis lainnya. Botol plastik banyak digunakan dibidang farmasi maupun makanan minuman. Beberapa hil keunggulan dari botol plastik yaitu tidak mudah pecah, ringan, harga relatif murah dan memudahkan dalam transportasi. Bahan baku yang digunakan dalam pembuatan botol plastik adalah Polivinilkhlorida, Polistirena, Polipropilen, Polietilen, Poliester. Dimana masing-masing resin mempunyai keunggulan dan kelemahan, yang akan disesuaikan dengan penggunaannya.

Dengan demikian botol plastik dipandang efisien bila dipakai sebagai pengemas, sehingga kita perlu mengetahui Rancang Bangun Pabrik Boto Plastik.

\section{MATERI DAN METODE PENELITIAN}

\section{Materi}

Materi yang digunakan dalam penelitian ini adalah data yang diperoleh dari studi pustaka dan survei di perusahaan untuk mengetahui proses pembuatan botol plastik. Data tentang spesifikasi peralatan diperoleh dari distributor permesinan.

\section{Metode Penelitian}

Data yang diperoleh diolah dengan menggunakan metode menurut Peter dan Thimmerhaus, 1978, sehingga dapat diketahụi :

- Persentase batas rugi laba

- Kapasitas pengembalian modal

- Waktu minimal untuk pengembalian modal

\section{HASIL DAN PEMBAHASAN}

a. Kegunaan dan pemasaran

$\begin{array}{ll}\text { Kegunaan } & : \text { Pengemas minuman } \\ \text { Pemasaran } & : \text { kebutuhan dalam negeri }\end{array}$

b. Spesifikasi Produk

$\begin{array}{ll}\text { Bentuk } & : \text { botol } \\ \text { Kapasitas penuh } & : 1000 \mathrm{cc} \\ \text { Warna } & : \text { putih } \\ \text { Tebal } & : \pm 0,13 \mathrm{~mm} \\ \text { Berat } & : \pm 77 \mathrm{~g} \\ \text { Bahan } & : \text { Polietilen food grade }\end{array}$

c. Diagram alir proses produksi botol plastik

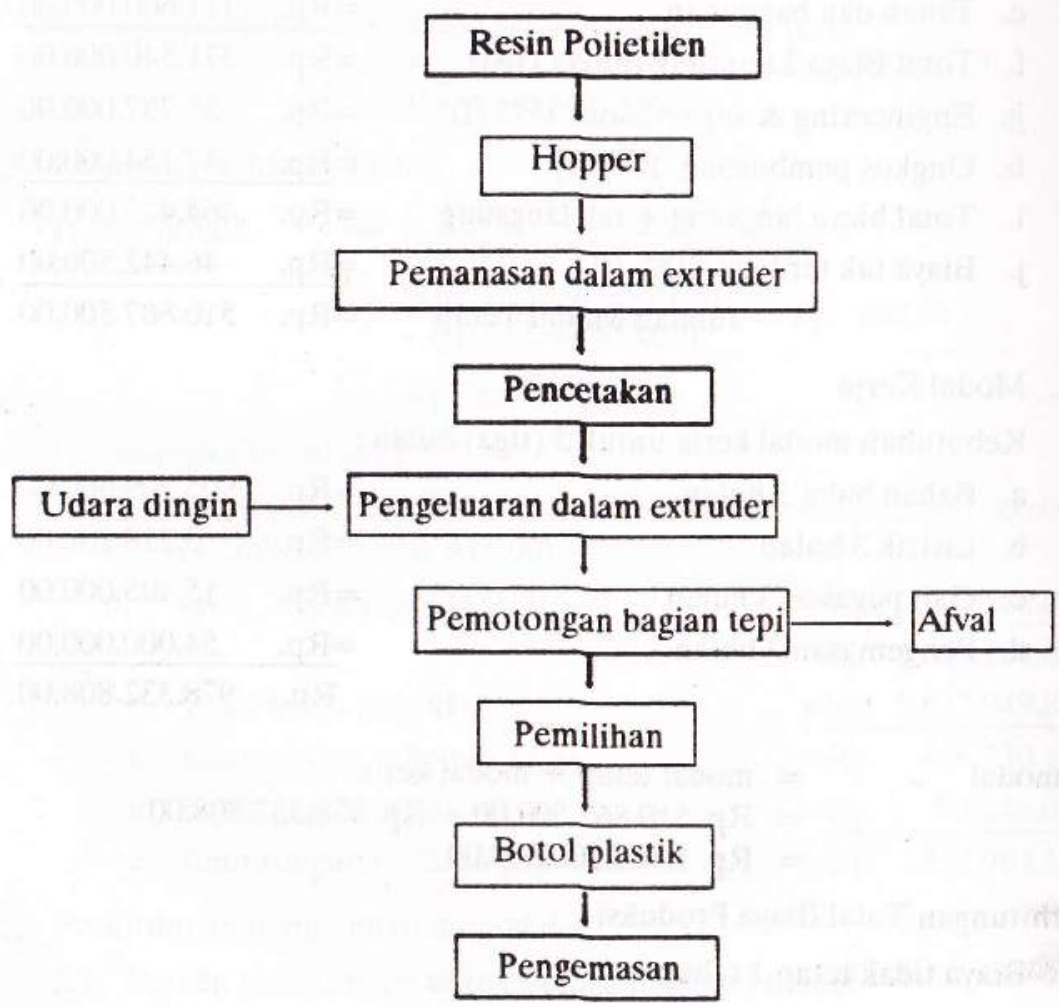




\section{PERHITUNGAN EKONOMI}

Hasil yang didapat dari perhitungan ekonomi ini akan memberikan gamaran berapa besarnya modal yang dibutuhkan untuk mendirikan industri botol lastik. Dalam perhitungan ini 1 tahun 288 hari kerja efektif, dan afval yang diasilkan dijual.

\section{Perhitungan modal}

1.1. Modal tetap
a. Harga peralatan
b. Perawatan, $10 \%$ (a)
c. Service fasilitas \& yard improvement, $10 \%$ (a)
d. Instalasi listrik, $10 \%$ (a)
e. Tanah dan bangunan
f. Total Biaya Langsung (direct cost)
g. Engineering \& supervision, $15 \%$ (f)
h. Ongkos pemborong, $10 \%$ (f)
i. Total biaya langsung + tak langsung
j. Biaya tak terduga, $10 \%$ (i) Jumlah Modal Tetap

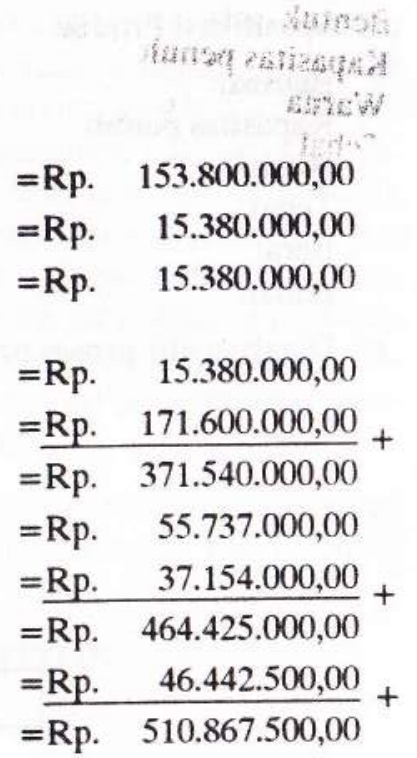

1.2. Modal Kerja

Kebutuhan modal kerja untuk 3 (tiga) bulan :
a. Bahan baku 3 bulan
=Rp. $\quad 905.709 .600,00$
b. Listrik 3 bulan
=Rp. $\quad 3.218 .208,00$
c. Gaji pegawai 3 bulan
=Rp. $\quad 15.405 .000,00$
d. Pengemasan 3 bulan
$\begin{array}{cr}=\text { Rp. } & 54.000 .000,00 \\ \text { Rp. } & 978.332 .808,00\end{array}$

Cotal moda

$=$ modal tetap + modal kerja

$=$ Rp. $510.867 .500,00+$ Rp. $978.332 .808,00$

$=$ Rp. 1.489.200,308,00

Perhitungan Total Biaya Produksi

2.1. Biaya tidak tetap 1 tahun
a. bahan baku 1 tahun
b. Pengemas 1 tahun
c. Listrik 1 tahun

2.2 Biaya Tetap 1 Tahun

a. Gaji 1 tahun

b. Pemeliharaan, $2 \% \mathrm{X}$ modal tetap

c. Bunga modal $15 \% \mathrm{x}$ modal tetap $18 \%$ x modal kerja

d. Penyusutan, $8 \% \mathrm{x}$ modal tetap

e. Biaya umum, $10 \% \mathrm{x}$ gaji 1 tahun
$=$ Rp. $\quad 2.888 .580,00$

=Rp. $\quad 172.777 .000,00$

$=\underline{\text { Rp. } \quad 10.307 .097,00}+$

Rp. $3.071 .664 .597,00$

$=$ Rp. $\quad 61.620 .000,00$

$=$ Rp. $\quad 29.784 .006,16$

=Rp. $\quad 146.749 .921,20$

=Rp. $\quad 176.099 .905,34$

=Rp. $\quad 40.869 .400,00$

$\begin{array}{cr}=\text { Rp. } \quad 6 \cdot 162 \cdot 000,00 \\ \text { Rp. } & 461 \cdot 285 \cdot 232,70\end{array}$

Total biaya produksi = Biaya tidak tetap + biaya tetap

= Rp. 3.071.664.597 + Rp. 461.285.232,70

$=$ Rp. $3.532 .949 .829,00$

3. Perhitungan harga pokok

$$
\begin{aligned}
\text { Harga pokok } & =\frac{\text { Total biaya produksi }}{\text { Jumlah produksi pertahun }} \\
& =\frac{\text { Rp. } 3 \cdot 532.949 .829,00}{\text { Rp. } 12.400 .000,00}=R p \cdot 284,91 \\
& =\text { Rp. } 285.000,00
\end{aligned}
$$

4. Perhitungan keuntungan
a. Hasil penjualan 1 tahun $(12.400 .000 \times$ Rp. 315,00$)$ afval $10 \%$ a Rp. $1.000,00$
b. Total biaya produksi
c. Keuntungan sebelum pajak
d. Pajak perusahaan $20 \%$
e. Keuntungan sesudah pajak

$$
\begin{aligned}
& =\text { Rp. } 3.906 \cdot 000.000,00 \\
& =\text { Rp. } \quad 93.180 .000,00 \\
& \hline \text { Rp. } 3.999 .180 .000,00
\end{aligned}
$$

5. Perhitungan pengembalian modal

5.1. Persen keuntungan untuk mengembalikan modal

Vol. IX No. 16 Tahun 1993/1994 
a. Sebelum pajak

$=\frac{\text { Keuntungan sebelum pajak }}{\text { Total modal }} \times 100 \%$

$=\frac{\text { Rp. } 466.230 .171}{\text { Rp. } 1.489 .200 .308,00} \quad x 100 \%$

b. Sesudah pajak

$=\frac{\text { Keuntungan sesudah pajak }}{\text { Total modal }} \times 100 \%$

$=\frac{\text { Rp. 372.984.136 }}{\text { Rp. } 1.489 .200 .308,00} \times 100 \%$

$=25,04 \%$

5.2. Waktu pengembalian modal

Total modal

$=\overline{\text { Keuntungan sesudah pajak + Penyusutan }} x 1 \mathrm{th}$.

Rp. $1.489 .200 .308,00$

$=$ Rp. 466.230.171,00+Rp. 40.869.400,00 $\times 1$ th

$=2$ th. $11 \mathrm{bl}$.

b. Sesudah pajak

$=\frac{\text { Total modal }}{\text { Keuntungan sebelum pajak }+ \text { penyusutan }} x 1 \mathrm{th}$.

$=\frac{\text { Rp. } 1 \cdot 489 \cdot 200 \cdot 308,00}{\text { Rp. } 372.984 .136,00+\text { Rp. } 40.869 .400,00} \times 1$ th.

$=3$ th. $7 \mathrm{bl}$.

Perhitungan Batas Rugi Laba

6.1. Nilai batas rugi laba

$$
\begin{aligned}
& =\frac{\text { Biaya tetap }}{1-\frac{\text { Biaya tidak tetap }}{\text { Penjualan }}} \\
& =\frac{\text { Rp. } 461.285 .232,70}{1-\frac{\text { Rp. } 3.071 .664 .597,00}{\text { Rp. } 3.999 .180 .000,00}}
\end{aligned}
$$

$=$ Rp. $1.988 .929 .421,0$

6.2. Persentase batas rugi laba $=\frac{\mathrm{Rp} \cdot 1 \cdot 988.929 .421,00}{\mathrm{Rp} \cdot 3.999 .180 .000,00} \times 100 \%$

$$
=49,73 \%
$$

6.3. Kapasitas batas rugi laba $=49,73 \times 12.400 .000$ buah
$=6.166 .250$ buah

\section{Kurva Batas Rugi Laba}

Biaya tidak tetap

Biaya tetap

Total Biaya Produksi

Total Penjualan

Persentase batas rugi laba

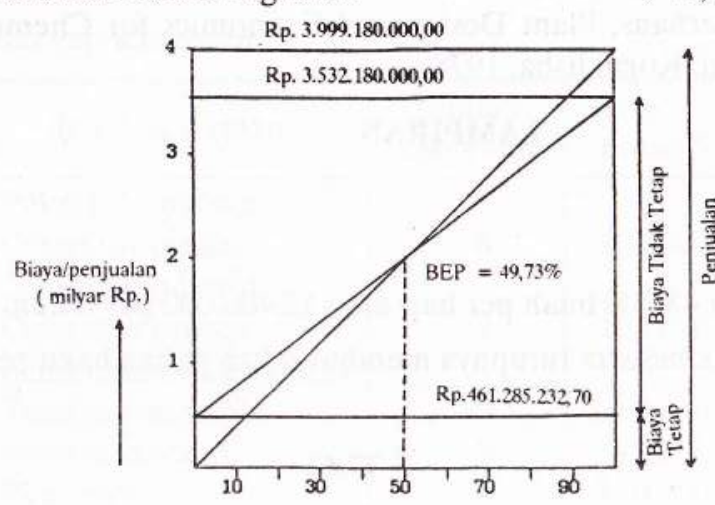

KESIMPULAN

Berdasarkan perhitungan analisis ekonomi dapat disimpulkan sebagai berikut :

- Dengan kapasitas produksi 43.200 buah per hari atau 12.400 .000 buah per tahun dibutuhkan modal sebesar Rp. 1.489.200.308,00 yang terdiri dari modal tetap Rp. 510.867.500,00 dan modal kerja Rp. 978.332.808,00

- Tenaga kerja yang diserap sebanyak 52 orang.

- Biaya produksi 1 tahun sebesar Rp. 3.532.949.829,00 maka diperoleh harga pokok produksi Rp. 285,00 per buah.

- Apabila produk dijual dengan harga Rp. 315,00 per buah, maka keuntungan sebelum pajak $31,30 \%$ dan keuntungan sesudah pajak $25,04 \%$, waktu pengembalian modal sebelum pajak 2 tahun 11 bulan dan sesudah pajak 3 tahun 7 bulan, sehingga diperoleh persentase batas rugi laba $49,73 \%$. 


\section{DAFTAR PUSTAKA}

Akira Kishimoto, The Composite Research and Development Center of 'I Oyo Sulian and Toyo Kohan Co.

Arum Yuniari dkk, Laporan Penelitian Rancang Bangun Perekayasaan Industri Awal Botol Susu Sapi Segar dari Bahan Plastik, BBKKP, 1991.

Perry's, Chemical Engineer's Handbook, third edition.

Peter and Thimmerhaus, Plant Design and Economics for Chemical Engineer, Mc Graw Hill, Kogakusha, 1978.

\section{LAMPIRAN}

Bahan Baku

Kapasitas produksi 43.200 buah per hari atau 12.400 .000 per tahun.

1 buah botol plastik beserta tutupnya membutuhkan bahan baku resin polietilen $77,65 \mathrm{~g}$.

$$
77,65
$$

Bahan baku 1 tahun

$$
\begin{aligned}
& =\frac{12.400 .000 \times}{1000} \times \frac{\text { Rp. } 3.000,00}{} \\
& =\text { Rp. } 2.888 .580 .000,00
\end{aligned}
$$

Utilitas

Kebutuhan listrik tiap hari 371,2 Kwh, dimana tiap Kwh taripnya Rp. 96,00 dan biaya beban tiap bulan Rp. $3.680,00$

Listrik 1 tahun

$$
\begin{aligned}
= & (288 \times 371,2 \times \text { Rp. } 96,00) \\
& (12 \times \text { Rp. } 3.680,00)
\end{aligned}
$$

= Rp. 10.307.097,60

\section{Tanah dan bangunan}

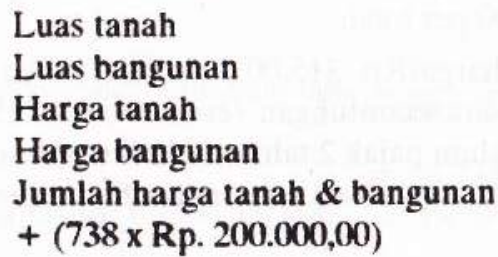

\section{Pengemasan}

Dalam 1 hari memproduksi 43.200 buah, tiap 36 buah dikemas dalam 1 dos

\begin{tabular}{|c|c|c|c|c|}
\hline No & Jenis pekerjaan & $\begin{array}{l}\text { Jumlah } \\
\text { karyawan }\end{array}$ & $\begin{array}{l}\text { Gaji/bulan/ } \\
\text { orang,Rp. }\end{array}$ & $\begin{array}{c}\text { Jumlah gaji } \\
\text { bulan, Rp. }\end{array}$ \\
\hline I. & Pekerja pabrik & & & \\
\hline 1. & $\begin{array}{l}\text { Operator proses } \\
\text { pembuatan botol }\end{array}$ & 6 & $100.000,00$ & $600.000,00$ \\
\hline 2. & $\begin{array}{l}\text { Operator proses } \\
\text { pembuatan tutup botol }\end{array}$ & 3 & $100.000,00$ & $300.000,00$ \\
\hline 3. & Tenaga pengemas & 10 & $50.000,00$ & $500.000,00$ \\
\hline 4. & Maintenance & 3 & $75.000,00$ & $225.000,00$ \\
\hline 5. & Pengawas & 3 & $150.000,00$ & $450.000,00$ \\
\hline \multirow[t]{2}{*}{6.} & \multirow[t]{2}{*}{ Gudang } & 8 & $75.000,00$ & $450.000,00$ \\
\hline & & 33 & & $2.525 .000,0$ \\
\hline $\begin{aligned} 11 . \\
1 .\end{aligned}$ & $\begin{array}{l}\text { Pekerja Kantor } \\
\text { Manajer }\end{array}$ & 1 & $800.000,00$ & $800.000,00$ \\
\hline 2. & Manajer produksi & 1 & $400.000,00$ & $400.000,00$ \\
\hline 3. & Manajer pemasaran & 1 & $300.000,00$ & $300.000,00$ \\
\hline 4. & Manajer administrasi & 1 & $250.000,00$ & $250.000,00$ \\
\hline 5. & Staf pemasaran & 2 & $150.000,00$ & $300.000,00$ \\
\hline 6. & Staf administrasi & 2 & $125.000,00$ & $250.000,00$ \\
\hline 7. & Kepala gudang & 1 & $100.000,00$ & $100.000,00$ \\
\hline 8. & Keamanan & 6 & $50.000,00$ & $300.000,00$ \\
\hline 9. & Tenaga kebersihan & & $40.000,00$ & $120.000,00$ \\
\hline \multirow[t]{2}{*}{10.} & \multirow[t]{2}{*}{ Sopir } & 1 & $65.000,00$ & $65.000,00$ \\
\hline & & 19 & & $2.610 .000,00$ \\
\hline & Jumlah I dan II & 52 & & $5.135 .000,00$ \\
\hline
\end{tabular}
karton, tiap 1 dos karton harganya Rp. 500,00

$$
\begin{aligned}
\text { Kebutuhan pengemas } & =\frac{90 \times 43.200 \times \mathrm{Rp} .500,00}{36} \\
& =\text { Rp. } 54.000 .000,00
\end{aligned}
$$

\section{Peralatan}

$$
\text { Jumlah harga peralatan }=\text { Rp. } 153.800 .000,00
$$

6. Jumlah dan gaji karyawan

Vol. IX No. 16 Tahun 1993/1994 